\title{
A PAIXÃO de CLARA E ALICE: RESISTÊNCIA E DESEJO NO ROMANCE QUARENTA DIAS (MARIA VALÉRIA REZENDE, 2014) E NO MELODRAMA AQUARIUS (KLÉBER MENDONÇA FILHO, 2016).
}

\author{
THE PASSION OF CLARA AND ALICE: RESISTANCE AND DESIRE IN \\ QUARENTA DIAS (MARIA VALÉRIA REZENDE'S NOVEL, 2014) AND \\ AQUARIUS (KLÉBER MENDONÇA FILHO'S MELODRAMA, 2016).
}

\section{LA PASIÓN DE CLARA Y DE ALICIA: RESISTENCIA Y DESEO EN LA NOVELA QUARENTA DÍAS (MARIA VALÉRIA REZENDE) Y EN EL MELODRAMA AQUARIUS (KLÉBLER MENDONÇA FILHO).}

\author{
Ricardo Gaiotto de Moraes \\ PUC-Campinas
} ricardo.moraes@puc-campinas.edu.br

\section{RESUMO}

O livro Quarenta Dias (Maria Valéria Rezende, 2014) e o filme Aquarius (Kléber Mendonça Filho, 2016) têm como ponto de interseção a resistência de suas protagonistas, mulheres aposentadas e idosas que resistem às investidas da sociedade de seus próprios filhos. Este artigo tem como objetivo comparar livro e filme, atentando-se para questões como: as representações da mulher idosa, considerando a elaboração formal nesses dois sistemas semióticos distintos; as referências à memória e aos arquivamentos pessoais; a relação das pessoas com os locais e as memórias deles e delas. Para elaborar tais problemas serão tomados como base os estudos sobre a escrita de si e as formas do diário (LEJEUNE, 2014), a constituição da memória a partir dos locais (ASSMANN, 2011) e a constituição do gênero melodrama no cinema latinoamericano (SADLIER, 2009).

PALAVRAS-CHAVE: Cinema Brasileiro; Literatura Brasileira; Memória; Melodrama. 


\section{ABSTRACT:}

Quarenta Dias (2014), a Brazilian novel written by Maria Valéria Rezende, and Aquarius (2016) a Brazilian-French film directed by Kléber Mendonça Filho, have as intersection point the resistance of their protagonists against people and situations, which threaten her desires and individuality. This article aims to compare book and film, focusing on issues such as the representations of the elderly woman, considering the formal elaboration in these two distinct semiotic systems; references to memory and personal archives; the relationship of people to their places and their memories. In order to elaborate these problems, this article takes as basis the studies on the written form of diary (LEJEUNE, 2014), the constitution of the memory related to specific places (ASSMANN, 2011) and the constitution of the genre melodrama in Latin American films (SADLIER, 2009).

KEY-WORDS: Brazilian Film; Brazilian Film; Memory; Melodrama.

\section{RESUMEN}

La noveala brasileña Quarenta Dias (2016), escrita por Maria Valéria Rezende, y Aquarius (2016), una película francesa-brasileña dirigida por Kléber Mendonça Filho, tienen como punto de intersección la resistencia de sus protagonistas; mujeres jubiladas y ancianas que se resisten a las embestidas de la sociedad de sus propios hijos. Este artículo pretende comparar el libro y la película, prestando atención a cuestiones como: las representaciones de la mujer mayor, teniendo en cuenta la elaboración formal de estos dos sistemas semióticos distintos; las referencias a la memoria y a los archives personales; a la relación de las personas con sus lugares y sus recuerdos. Para abordar estos problemas, este artículo toma como base los estudios sobre la forma escrita del diario (LEJEUNE, 2014), la constitución de la memoria relacionada con lugares específicos (ASSMANN, 2011) y la constitución del género melodrama en el cine de América Latina (SADLIER, 2009).

PALABRAS CLAVE: cine brasileño; literatura brasileña; memoria; melodrama 


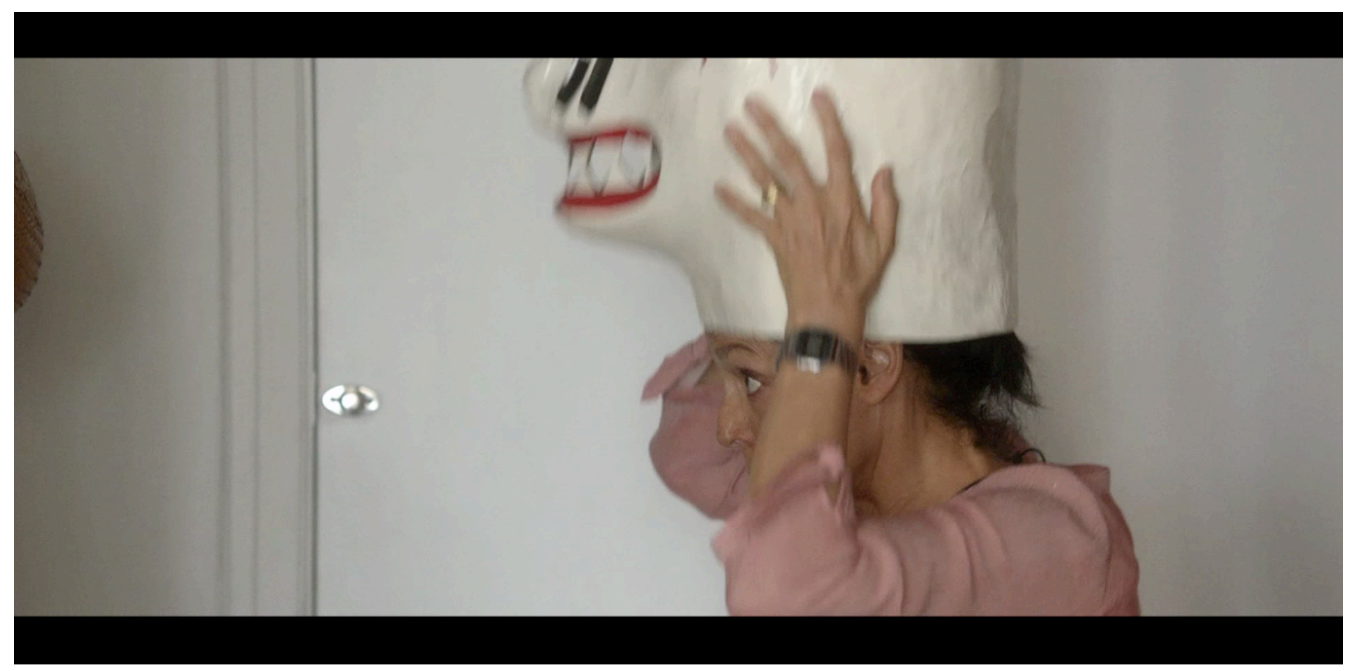

Aquarius, 2016.

$1: 40: 38$

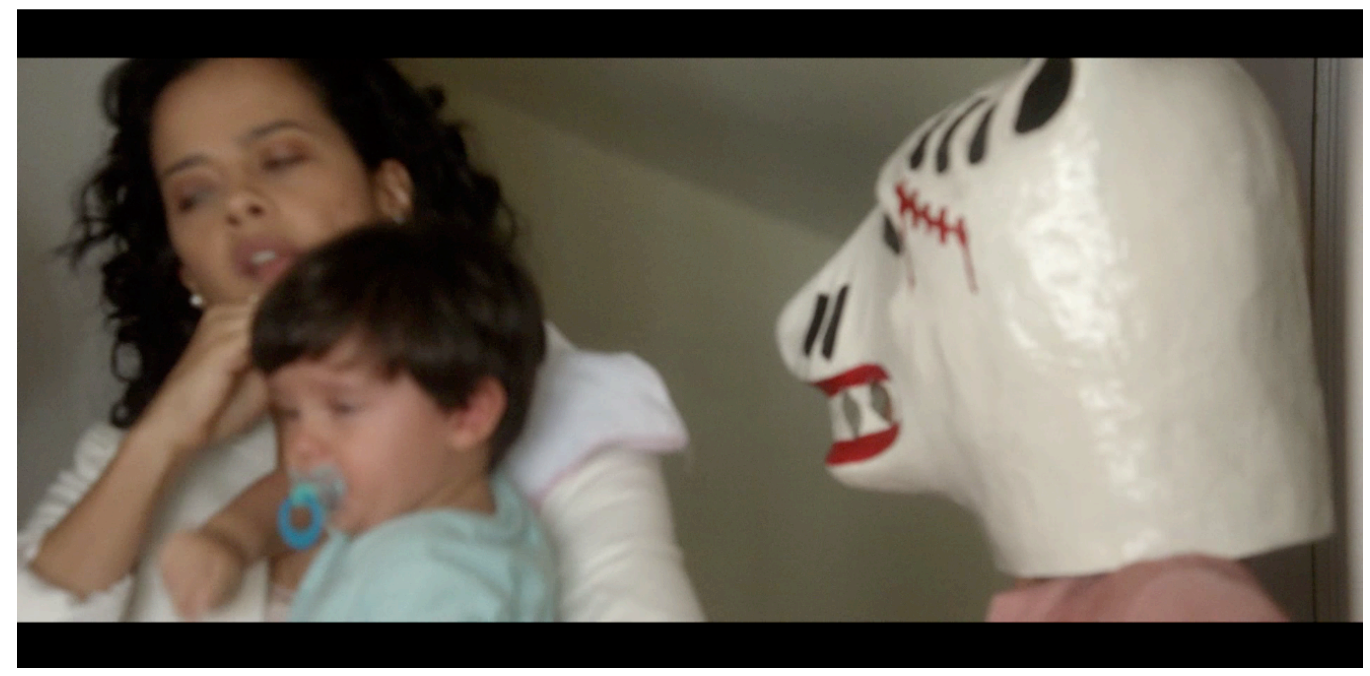

Aquarius, 2016.

$1: 40: 45$

"Mãínha, tenho uma coisa importantíssima pra lhe dizer. Chegou a hora da senhora virar avó ![...] [ALICE:] Pra quando vai ser? Ela 
[CLARA] se mexeu, inquieta, hesitou e finalmente respondeu Vai depender da senhora, Mãínha” (Rezende, 2014: 25-26).

\section{INTRODUÇÃO}

Aquarius, dirigido por Kléber Mendonça Filho, foi indicado à palma de ouro de melhor filme e Sonia Braga, no papel de Clara, como melhor atriz no Festival de Cannes de 2016. Ainda que não tenha vencido nas categorias indicadas, as qualidades do filme repercutiram e os atores protagonizaram uma cena polêmica: na première, carregavam cartazes em que protestavam contra o "golpe de estado em curso no Brasil", o impeachment da presidenta Dilma Rousself, processo conduzido, por deputados e senadores, em grande número, denunciados por corrupção.

O gesto de protesto e resistência no tapete vermelho do festival se relacionava dramaticamente ao tema do melodrama. Nele, Clara é uma mulher de 65 anos que resiste, à revelia do mercado e do desejo dos próprios filhos, em vender seu apartamento no edifício "Aquarius", na praia de Boa Viagem, no Recife, para a construtora Bonfin, que comprara os demais apartamentos. Clara, sozinha, é a moradora que resiste à especulação imobiliária, à derrubada de seu lar e à construção do condomínio "Novo Aquarius", pois o apartamento parece constituir sua identidade.

Quarenta Dias, escrito por Maria Valéria Rezende e publicado em 2014, no ano seguinte recebeu o Jabuti, categorias romance e Livro do Ano de Ficção, maior prêmio literário do mercado editorial brasileiro. No romance escrito em forma de memórias, Alice deixa sua vida em João Pessoa, onde, aposentada, vivia num apartamento alugado com seus pertences e era professora, para morar próxima a sua filha, em Porto Alegre. A filha e o marido, professores universitários, resolveram ter um filho. A filha pede e, com chantagens (diretas e indiretas) envolvendo toda a famílias, acaba conseguindo que a mãe se mude para Porto Alegre. Alice no momento da escritura, posterior às ações enunciadas, sente-se "fora do lugar", pois a mobília, parte das roupas, os pertences e lugares que a constituíam ficaram longe. O novo apartamento foi decorado pela filha, é um lugar marcado pela impessoalidade da decoração da moda. 
As identificações se Alice borram, ela está em um lugar em que não queria estar, para uma função coadjuvante que não queria desempenhar, subjugada pelo imperativo da filha. A filha bem-sucedida no mercado de trabalho empurra a mãe para uma posição próxima àquela que era relacionada às mulheres de meados do século $\mathrm{XX}$ : cuidar dos filhos e, por extensão, dos netos. É na rua que essa mulher, agora às margens da sociedade vai se reconhecendo, neste mundo que não lhe era familiar. Um dos temas mais fortes no livro parece ser a resistência dessa mulher que não podia ocupar o lugar que não queria.

O livro Quarenta Dias e o filme Aquarius têm como ponto de interseção a resistência de suas protagonistas, mulheres aposentadas e idosas que resistem às investidas da sociedade e dos próprios filhos. As duas narrativas parecem convergir, portanto, para uma representação da mulher idosa, cujos desejos estão em constante tensão com o mundo representado pelos filhos, por não corresponderem à imagem do papel social que deveriam ocupar a partir do estereótipo que a própria família lhes traçou.

\section{OBJETIVOS E METODOLOGIA}

Este artigo tem como objetivo fazer uma análise do romance-memória e do melodrama, marcando aproximações entre as duas narrativas, examinando: as representações da mulher idosa, considerando a elaboração formal nesses dois sistemas semióticos distintos; as referências à memória e ao arquivo que aparecem em Quarenta dias, por meio da organização em diário do romance, e em Aquarius por meio do flashback, das recordações e dos objetos que compõem o cenário mais recorrente na história; a constituição do gênero memórias e melodrama nas duas narrativas e o cruzamento entre recepção e biografia das personagens.

Para elaborar a análise, o artigo lançará mão dos estudos sobre a escrita de si e as formas do diário (LEJEUNE, 2014), a constituição da memória a partir dos locais (ASSMANN, 2011) e a constituição do gênero melodrama no cinema latino-americano (SADLIER, 2009). A partir de leitura e discussão dos conceitos apresentados nestes textos, o será uma análise de cunho qualitativo e comparativo, respeitando a diferença de sistemas semióticos, do romance Quarenta Dias e do melodrama Aquarius. 


\section{ANÁLISE}

A enunciação em Quarenta Dias começa depois que Alice, a protagonista, volta para seu apartamento em Porto Alegre onde fora instalada pela filha. Dirige-se à boneca Bárbie da capa do caderno que trouxe de seu apartamento em João Pessoa. O caderno é tábula rasa, em que inscreverá as lembranças do que tem passado depois de chegar a Porto Alegre, e, ao mesmo tempo, um vestígio da resistência de deixar sua vida na Paraíba, local que considerava como lar. É no espaço das linhas do caderno que tentará organizar suas memórias:

Pronto! Contar a mim mesma, tim-tim por tim-tim, o que me anda acontecendo, desabafar com a boneca loira e o papel pautado, moucos e calados, incapazes de assustar-se, nem de dizer que estou doida, nem me mandar fazer psicoterapia ou sugerir um curso de dança de salão pra fazer amigos, um oficina literária para me ocupar (Rezende, 2014: 14).

A cena da escritura se dá em tempo real, no entanto trata das memórias da narradora protagonista. O livro é organizado em registros diários, mas a quantidade de capítulos (32) não corresponde ao número de dias em que Alice habitou as ruas de Porto Alegre. A marcação da sequência temporal do registro é construída pela materialidade do espaço em branco entre um registro e outro, pelas epígrafes com citações de outros autores brasileiros - sobretudo contemporâneos -, pelas marcas de interlocução com a boneca e comentários sobre o gesto da escrita:

\footnotetext{
"Chega de escrever qualquer coisa, ainda mais que você [Barbie] não dá a mínima pro que eu estou dizendo. Você só sabe inglês, não é?, ou nem isso? "Good night, Barbie” (Rezende, 2014: 56).

"Good morning, Barbie", sabe que até deu pra dizer isso com certa naturalidade? Bom encontrar você de novo aqui, a caneta, a possibilidade de continuar nesse limbo tranquilizante da escrita desenfreada (Rezende, 2014: 59).
}

O livro é um quase diário das memórias dos dias em que Alice viveu na rua. É um quase diário, pois ainda que apresente "uma série de vestígios" com a "intenção de balizar o tempo através de uma sequência de referências" (Lejeune, 2014: 300), trata-se de um 
registro memorialístico feito em um tempo posterior ao ocorrido. De acordo com as categorias definidas por Lejeune para a autobiografia, seria possível acrescentar que é um simulacro de quase diário, pois não se estabelece com o leitor formalmente o "pacto autobiográfico" (Lejeune, 2014: 33). Isso porque o nome da autora e da narradora não coincidem, afastando também o livro do enquadramento no gênero autoficção. Apesar disso, mesmo que dentro do pacto romanesco, a força da narrativa está na construção do das memórias do eu.

Para compor a série de vestígios do quase diário, os episódios são, em grande parte dos capítulos, abertos por traços que atestam a situação narrada. Há abundância de folhetos, cartões, anúncios que são "colados" nas páginas do diário. Embora não se enquadre em autoficção, pois além da não coincidência do nome, a biografia de Alice não parece a de Maria Valéria Rezende (a autora é uma freira e não teve uma filha), a matéria-prima da narrativa vem da experiência da autora. Em uma entrevista (Rodrigues, 2014), ela afirma que a condição de Alice, mulher idosa aposentada que deixa sua vida para ajudar a cuidar do neto, veio das confissões que, como freira, escutava:

\footnotetext{
Pelo fato de ser freira, recebo muita confidência. E fui me dando conta de toda uma problemática que estava surgindo para mulheres da minha geração, que foram para a rua trabalhar, criaram os filhos, deram um duro danado, adiaram uma porção de projetos e, de repente, quando chega a hora de aposentar, elas são convocadas para serem avós profissionais porque os filhos têm suas carreiras e nenhuma disposição de fazer sacrifícios (Rodriguez, 2014).
}

Para além das confissões, Alice é uma professora "poli" (polivalente, professora de ensino fundamental 1), que leciona também francês. Esses dados se interseccionam com parte da biografia de Maria Valéria Rezende que também é formada em letras e ensinava francês. Além disso, passou 15 dias na rua para elaborar a trajetória de Alice que, em busca do filho com paradeiro desconhecido de uma colega da Paraíba, permanece sem voltar para casa perguntado por Cícero Araújo.

Perguntei para todos onde eu poderia encontrar Cícero Araújo, que era invenção minha, e ia atrás dele. Voltava para casa à noite, mas cheguei a dormir em rodoviária, aeroporto e hospital, onde tinha abrigo, porque uma velhinha de 70 anos não pode abusar e eu não estava para fazer sacrifício da minha vida por causa de uma ideia de romance (Rodriguez, 2014). 
Aquarius não é autoficção nem autobiografia, o contrato estabelecido com o leitor é o da ficção. Dividido em três capítulos "O cabelo de Clara", "O amor de Clara" e "O câncer de Clara" - a narrativa começa em flashback, o que de certa forma já situa a importância da temática da memória no enredo. Ao som de "Another one bites the dust", do Queen, jovens casais na praia, Clara e seu marido, dentro de um Opala da Chevrolet, aproveitam o tempo. A próxima cena é a de uma festa de 70 anos de Tia Lúcia no apartamento do condomínio Aquarius, na orla da praia de Boa Viagem, Recife. É a primeira tensão entre gerações, crianças homenageiam a septuagenária pelos estudos que havia desenvolvido. A câmera focaliza Tia Lúcia e depois um móvel antigo - uma cômoda -, aparecem então cenas de sexo de quando Lúcia era jovem. A aniversariante interrompe a homenagem, em tom de brincadeira, gostaria de ser lembrada também pela revolução sexual que eu representava. O desejo e a lembrança do sexo de Tia Lúcia se contrapõem à memória que os convivas queriam ressaltar, o desejo dela havia sido apagado, de certa forma, pela comemoração. Entra, então, em cena, Clara jovem. O marido a homenageia pela resistência ao câncer de mama que tivera.

A próxima cena focaliza os convivas dançando ao som de "Toda menina baiana de Gilberto Gil”. A passagem do tempo para o presente da enunciação, os anos 2015, se dá ao som de Gil, a câmera viaja pela sala vazia, do mesmo apartamento da festa. Clara (Sonia Braga) aparece fazendo alongamento, conversa com Ladjane, a empregada, e então desliga o toca disco. O filme passa à sequência temporal cronológica do enunciado.

Se Maria Valéria Rezende apropria-se de experiências pontuais para a matéria prima de seu romance, também o diretor Kléber Mendonça Filho relata que o faz em seu filme. Em entrevista a Cahiers du Cinema (Lepastier; Schweitzer, 2016), ele conta que, além da familiaridade com Recife e com a paisagem da praia de Boa Viagem, local onde a narrativa foi filmada, muito da protagonista Clara teria vindo de sua mãe, uma mulher forte e que também foi acometida por um câncer. A resistência em relação aos imperativos do mercado imobiliário, o argumento do enredo, aparecera da observação das questões econômica e políticas do Recife, e também de um caso pessoal. Quando estava procurando por um novo lugar para morar, percebeu ser a habitação que escolhera bem mais barata que aquelas preferidas pelos outros, mas detestadas por ele. 
Et puis une histoire personnelle: il y a quelques années, nous cherchions un nouveau logement, et l'endroit que nous aimions était meilleur marché que celui où tout le monde voulait habiter, e que nous détestions. Clara vit dans un appartmente très simple et agréable, et quelqu'un décide qu'il doit être détruir. [...] C'est pareil avec Clara, on veut lui prendre son appartment et elle répond: «But I'm using it!» (Lepastier; Schweitzer, 2016: 42).

A resistência de Clara à especulação imobiliária é incorporada no filme pela guerra fria declarada entre ela e Diego (Humberto Carrão), que dirige o projeto do novo condomínio - o "Novo Aquarius" - e é neto do dono da construtora. Eles objetivam comprar o apartamento de Clara, como fizeram com os outros do condomínio Aquarius, mas ela não aceita. É a única moradora que resiste. Diego, estudou business nos Estados Unidos, é jovem de família rica, ambicioso. Clara - com 65 anos, é viúva, tem três filhos e é crítica musical - num dos diálogos entre os dois, ela descreve, "Você faz aquele tipo passivo agressivo", ele retruca: "Eu faço o tipo focado. [...] Estou de volta [dos Estados Unidos] com sangue nos olhos". Mesmo que a velocidade da especulação imobiliária pareça historicamente vencer a batalha nas grandes cidades brasileiras ${ }^{1}$, nós, espectadores, somos levados pela força do filme a torcer por Clara, porque compreendemos que aquela luta a constitui. Isso porque o conflito entre Clara e Diego espraia-se da tensão entre especulação imobiliária, o capital, versus a manutenção da propriedade tradicional, e para a tensões geracionais, o que leva a posições antagônicas e agônicas em relação à "memória dos locais".

Aleida Assmann afirma, em Espaços da recordação (2011), que a expressão "memória dos locais" permite uma dupla leitura, pode se referir tanto à "memória que se recorda dos locais", quanto à "memória que está por si só situada nos locais" (Assmann, 2011: 317). No caso da relação simbólica de Clara com sua casa, esses dois sentidos parecem válidos, uma vez que, no filme, o apartamento de objeto acaba se transformando em sujeito da memória. Nele, a protagonista arquiva seus livros, seus vinis, seus álbuns de fotos e se apropria ativamente desses vestígios que constituem a duração da memória, transformando-se a casa em bastião contra o esquecimento e o apagamento. Para se proteger das investidas contra o seu desejo de permanecer no apartamento - quando

\footnotetext{
${ }^{1}$ No contexto brasileiro, a cidade de São Paulo pode ser tomada como um exemplo da voracidade da especulação imobiliária. Mesmo diante disso, Zé Celso Martinez Corrêa, um dos mais importantes nomes do teatro brasileiro, tem conseguido arregimentar uma grande resistência para a conservação do prédio e do entorno do Teatro Oficina, opondo-se à força do grupo empresarial liderado pelo empresário Sílvio Santos.
} 
Diego faz uma festa orgiática com som alto e no imóvel de cima, a primeira reação de Clara é sacar um de seus vinis e colocar no volume mais alto Fat bottomed girls, do Queen. Além disso, às vezes a câmera mostra em primeiro plano um detalhe do apartamento como a cômoda, móvel que no filme funciona como um apelo que dispara as recordações ${ }^{2}$ - como ocorrera no caso da tia septuagenária, é como se o lugar fosse dotado também de memória.

A relação de Clara com o apartamento não é compreendida nem mesmo pelos filhos que ali viveram parte da vida. Há uma cena em que os dois filhos e a filha reunidos mostram-se preocupados com o conforto e a segurança da mãe. Um deles pergunta como a mãe se sente, se está se estressando com a situação. Clara, com um palavrão, responde: "Eu disse que estou puta, quem está se preocupando são vocês". Aninha, a filha, afirma que a mãe deveria vender o apartamento, porque já não se poderia ter conforto naquele "prédio fantasma". Clara, com a mão no queixo olhando para cima, responde que filha não tinha limite nem sensibilidade e arremata: "Quando você gosta é vintage, quando não gosta é velho". Nesta cena pulsa o outro conflito pujante do filme: a tensão entre as gerações. Nomeada assim, essa tensão poderia ser considerada trivial, mas no filme, gera também um conflito - que já fora anunciado pela figura de Diego - a incapacidade para um determinado grupo - sobretudo daquele cujo projeto de vida tem como fim a praticidade, de compreender os sentidos da "memória do local" e seus significados.

Aleida Assmann (2011) afirma que convive, no discurso que compõe o romance $A$ letra escarlate (Nathaniel Hawthorne, 1850), tanto a valorização da resistência dos antigos moradores decididos a permanecerem em determinada porção de terra, quanto a percepção dessa resistência uma barreira "às exigências da mobilidade moderna" (Assmann, 2011: 320-321) e, portanto, ao progresso. No caso de Aquarius, essa tensão agônica também está presente, compreendida a partir de outras variáveis. Clara se vincula ao apartamento, que é o arquivo de suas identificações, e ao mesmo tempo luta pelo espaço, que lhe dá um papel ativo dentro desse mundo dos jovens refratário a ela por a considerar ultrapassada. Não se trata de uma personagem impermeável às novas tecnologias, se ela ainda escuta discos de vinis, aceita também as tecnologias de armazenamento digitais recentes, a tensão é de outra ordem. Além da necessidade de

\footnotetext{
2 «[...] la comode sera là, dans l'appartemente de Clara, comme um appel à ouvrir la source aux souvenirs" (TUILLIER, 2016, p. 41).
} 
manutenção do apartamento, Clara luta pelo próprio possibilidade de tomar decisões e de se manter ser desejante e atuante.

Em Quarenta Dias, Alice, ao se mudar, empurrada pela filha para Porto Alegre, perde, em parte, a batalha. Sua constituição como ser desejante e atuante é profundamente ferida, pois a filha, que representa neste caso a força do novo, ultrapassa as decisões e os desejos da mãe. Contraditoriamente, Norinha, a mulher que conseguira conquistar o mercado de trabalho tornando-se professora universitária em um país ainda muito machista, desloca a mãe que, resignadamente, muda-se para assumir o papel de avó, deixando o próprio emprego como professora. Também Alice tinha seu local em João Pessoa, ainda que o apartamento fosse alugado, a memória do local era testemunhada por alguns móveis, como:

[...] uma cadeira de balanço austríaca com a palinha gasta protegida por uma almofada de ponto de cruz, restos da casa da minha avó, onde eu tinha arriado pra ficar, amuada, assistindo ao rebuliço, à derrocada da minha vida tão boínha, e só pensando que, graças a Deus, não tinha ainda posto em prática a decisão de ter um gato, pobrezinho, o que seria dele naquela situação. (Rezende, 2014: 8).

Quando se muda para o imóvel providenciado pela filha não consegue reconhecer o apartamento como casa, mesmo que essa contenha os livros transportados pela mudança, agora estavam "encabulados naquele cenário emergente de novela de televisão, entre coisas impessoais" (Rezende, 2014: 41). A decoração impessoal e vazia faz com que ela se perca sem identificação. Poucos dias depois de chegar a Porto Alegre, a filha a convida para jantar, Alice descobre que os planos de gravidez da filha seriam adiados por conta de uma bolsa de pós-doutorado no exterior que Norinha recebera. Este fato é o estopim para o início da expiação de Alice pelas ruas de Porto Alegre. O contato com os habitantes da rua a faz conhecer Lola, mulher que carregava um carrinho "empanturrado de sobejos do consumismo dos outros" (Rezende, 2014: 196). A princípio, a narradora se assusta ao ver que aquela mulher a considerava como também uma moradora de rua:

Eu já devia parecer uma inegável moradora de rua. E não era, Barbie? Ainda não tinha me dado conta, mas já era, sim, tanto que lá pro meio da manhã ouvi um rangido próximo, senti movimento, alguém sentando bem junto de mim [...]. A mulher era bem mais velha que eu. [...] 
Era uma ruína, pobrezinha, pensei, até encará-la e perceber o brilho vivo, curioso e esperto dos olhos azuis, inacreditavelmente limpos e vivos, o azul, azul, o branco, perfeitamente branco. Fiquei chateada de que me acreditasse igual a ela, sim, moradora de rua, pedinte [...] (Rezende, 2014: 196).

Alice descobre posteriormente que Lola tinha uma casa herdada do marido que morrera. Apesar da casa em ruínas, a personagem descreve o local de maneira menos asséptica que o apartamento arranjado pela filha: "a casa de Lola [...] parecia arruinada, mas oferecia um simulacro de teto e uma sensação de proteção, como o cadeado no portão e o ressonar forte da castelã do meu lado" (Rezende, 2014: 231). Lola tinha um local, de certa forma, um arquivo para suas recordações, aquilo que Alice perdera, e é Lola quem manda Alice de volta da expiação ao apartamento: "Dorme que quando clarear tu vai, vai pra teu apartamento, pra tua filha única de mãe viúva, teu neto" (Rezende, 2014: 245). Apesar do tom melodramático que o livro pode assumir devido à perda inicial, aos poucos o diálogo com boneca Bárbie, o exercício da escrita da memória, e, de certa forma, a reconstituição do arquivo a partir da expiação reestabelecem sentidos para a vida de Alice, mas a cicatriz continua latente.

No caso de Clara, ceder à especulação imobiliária e vender o apartamento significaria perder toda a carga simbólica que este guarda e representa e, portanto, deixar-se vencer pelo desejo do outro. Esta luta de Clara contra uma força que parece hegemônica constitui um dos aspectos que dão força ao melodrama. Darlene Sadlier afirma serem os problemas de ordem familiar, que se estendem à ordem social, cuja carga sentimental aponta para uma ruptura com o patriarcalismo (Sadlier, 2009: 3) ${ }^{3}$, a marca do melodrama no cinema da América Latina. No caso de Aquarius, o elemento melodramático parecer apontar, em um primeiro plano, para uma tensão maniqueísta, identificada pela oposição Clara (manutenção da memória do local) x Diego (capitalismo imobiliário), no entanto a equação é mais complexa. Porque esse suposto

\footnotetext{
3 “ $[\ldots]$ in the film studies today, the term melodrama is nearly always used to designate films about domestic or family issues. Strongly associated with stars such as Bette Davis and Joan Crawford and with directors such as Douglas Sirk and Vincente Minelli, it also signifies a kind of emotional or stylistic excess that at least theoretically functions as a release from repressive Puritanism and patriarchy. [...] Latin America produced and continues to produce many films on this type, but the term melodrama has somewhat broader implications in countries such as Mexico, Argentina, and Brazil, where it refers not only to domestic dramas but also to historical epics in which family life is viewed in relation to larger national issues" (SADLIER, 2009, p. 3).
} 
maniqueísmo, que é aliás realçado pela cicatriz causada pelo câncer no corpo de Clara, é permeada pela coaparição de outras tensões.

Ladjane, a empregada doméstica de Clara, mora na região pobre de Recife, está, na maior parte do tempo na cozinha da patroa. Em uma das cenas, numa reunião familiar, Clara, vasculhando álbuns antigos, encontra a foto de uma empregada doméstica da família. Em um primeiro momento, ninguém se lembra do nome dela, Clara, então, se recorda: era a Jovita, que roubara as joias da mãe de Clara. O close-up corta parte da foto, aparece apenas o corpo de uma mulher negra vestida de empregada, o rosto não é mostrado. Ainda na mesma cena, Ladjane entra em cena, mais uma vez, a câmera, repetindo o enquadramento de Jovita, mostra apenas o corpo. Ela mostra a Clara e aos parentes a foto de seu filho que morrera atropelado por um motorista alcoolizado. Quando, ao final do filme, se descobre a sabotagem que a construtora estava fazendo com o edifício, depositando nos apartamentos vazios colmeias de cupins, Ladjane resolve não acompanhar a patroa: "Eu não vou, não."

Desde a escolha significativa das canções, passando da tensão familiar aos multifacetados problemas sociais, muitos são os aspectos melodramáticos na elaboração de Aquarius. A cena final do filme é de grande energia, os pedaços de madeira podre pela ação dos cupins que são jogados por Clara em cima da mesa diante das feições atônitas do dono da construtora e de seu neto fazem os espectadores vibrarem sentindose vingados. Clara, como o sobrinho mais novo ao lado - figura que ajuda deixar complexa as tensões do enredo, pois relativiza o conflito obrigatório entre as gerações -, ainda tem forças, resiste à imagem ao desejo alheio. O corte da cena e o fim do filme não apresenta fácil resolução, mas aumenta a complexidade da figura da mulher. Clara não é a idosa frágil da fantasia dos filhos, não vende o apartamento; não é a idosa que não entende a lógica da especulação, tanto entende que ao fim descobre em arquivos do governo indícios contra o dono da construtora; não é a idosa que não sentia mais desejo e que não deveria ter uma vida independente.

\section{CONSIDERAÇÕES FINAIS}

Quarenta Dias e Aquarius são retratos complexos de mulheres que resistem. Nas duas narrativas a marca dessa resistência se dá pelo texto ou pelas cenas que se organizam a partir da reencenação e reorganização das memórias e dos tempos. No caso do romance, a cena de escritura, que inclui o diálogo com a Barbie - boneca que representa a 
massificação da qual a protagonista quer se afastar e também a reificação do feminino -, é que tenta dramaticamente reorganizar o espaço, no qual a fronteira entre o familiar, a casa, e o estranho, a rua, se borram e constituem um duplo estranhamento. No caso do melodrama, é a permanência no apartamento, ilha da memória, que constitui a única via possível de se manter os vestígios que mantém a identidade.

No caso de Quarenta Dias e Aquarius, a intersecção entre o romance-memória e o melodrama se dá na medida que, ao focalizarem tão particularmente personagens individuais em suas rotinas e tensões, essas narrativas apontam para problemas sociais da mais absoluta atualidade: enquanto há um discurso que parece hipervalorizar as referências ao passado, pelo menos às memórias estetizadas e prontas para o consumo, há também um apagamento do que não é pretérito vendável. Filme e livro tentam escapar dessa lógica a partir da elaboração estética que causa no expectador comoção, mas também um estranhamento quase de culpa.

\section{REFERÊNCIAS BIBLIOGRÁFICAS E FÍLMICAS}

Assmann, A. (2011). Espaços da recordação: formas e transformações da memória cultural. Campinas (Brasil), Editora da Unicamp.

Lejeune, P. (2014). O pacto autobiográfico: de Rousseau à internet. 2a. ed. Belo Horizonte (Brasil), Editora UFMG.

Lepastier, J; Schweitzer, A. (2016). Le secret des lieux: entretien avec Kleber Mendonça Filho. Cahiers du cinema, no 725 , pp. 42-45.

Lescaux, E. e Ben Saïd, S. (produção), e Mendonça Filho, K. (direção). (2016). Aquarius. Brasil/França, Vitrine Filmes; SBS; CinemaScópio; Video Filmes; Globo Filmes. 1 DVD (140 min.).

Rezende, M. V. (2014). Quarenta dias. Rio de Janeiro (Brasil), Objetiva.

Rodrigues, M. F. (2014). Maria Valéria Rezende viveu na rua para escrever romance. In: $O$ Estado de S. Paulo, 02/05/2014. Disponível em http://cultura.estadao.com.br/noticias/geral,maria-valeria-rezende-viveu-na-rua-paraescrever-romance,1161541. (Acesso em 27/10/2017).

Sadlier, D. J. (org.) (2009). Latin American melodrama: passion, pathos and entertainment. Urbana; Chicago (Estados Unidos), University of Illinois Press.

Tuillier, L. (2016). Le vaisseau fantôme. Cahiers $d u$ cinema, $\mathrm{n}^{\mathrm{0}} 725$, pp. 40-41. 